\title{
Os Processos Avaliativos no Ensino de Matemática e os Documentos Oficiais
}

\author{
The Assessment Process in the Teaching of Mathematics and the Official Documents
}

Nome do autor ${ }^{1}$

Nome do outro autor se tiver ${ }^{2}$

\begin{abstract}
Resumo: Este artigo tem como objetivo investigar os processos avaliativos utilizados pelos professores, no ensino da Matemática, considerando as diretrizes da Base Nacional Comum Curricular e da Deliberação CEE 155/2017. Trata-se de um estudo de cunho qualitativo, descritivo-analítico, tendo como procedimento a realização de entrevistas semiestruturadas com professores que atuam numa escola particular. Apoiamo-nos, como referencial teórico, nos estudos de Telma Weisz que tratam das concepções de aprendizagem e de Hoffmann, Luckesi e Perrenoud que abordam o conceito de avaliação. Os dados coletados foram submetidos à análise e divididos em dois eixos: "fundamentos da ação docente e aprendizagem da docência" e "concepções de aprendizagem e os processos avaliativos". Constatamos, com a análise, que os professores não definem qual a concepção de aprendizagem que sustenta suas práticas pedagógicas. Além disso, eles afirmam que conhecem os documentos oficiais - Deliberação CEE 155/2017 e a BNCC -, mas não os utilizam, preferindo seguir as normas avaliativas institucionais.
\end{abstract}

Palavra-chave: Base Nacional Comum Curricular; Deliberação CEE 155/2017; Processos avaliativos. Ensino de Matemática.

\begin{abstract}
This article investigates the assessment processes. The main objective of this research was to investigate the assessment processes used by the teachers, in the teaching of Mathematics, considering the directives of the National Common Curricular Base and the Deliberation CEE 155/2017. The dissertation was characterized by a qualitative, descriptive-analytical approach, and the procedure was documental analysis, making use of semi-structured interviews, with teachers who work at private school. As a theoretical reference we used the teachings of Telma Weisz, authors who deal with the concepts of learning and the teachings of Hoffmann, Luckesi and Perrenoud who approach the concept of assessment. After the interviews, the data collected were submitted for analysis and divided into two axes: "fundamentals of teaching action and teaching learning" and "learning concepts and assessment processes". The analysis showed that teachers do not define which concept of learning supports their pedagogical practices. Moreover, they stated that they know the official documents - Deliberation CEE 155/2017 and the BNCC - but do not use them, preferring to follow the institutional assessment norms.
\end{abstract}

Key-words: Common National Curriculum Base; Deliberation CEE 155/2017; Evaluation Processes; Mathematics Teacher Training.

\section{Introdução}

Todo início de ano, os professores passam por um período de planejamento, em que há palestras, reuniões por área, discussões de caso e o acolhimento dos novos professores na instituição de ensino. Geralmente, nos momentos de discussão, uma temática abordada é o estabelecimento, no calendário, de quando ocorrerá o processo avaliativo. No decorrer do ano letivo, os professores

\footnotetext{
1. Em nota de rodapé, são inseridos os dados do autor. (e. g. Professor do Departamento de Matemática da PUC-SP. E-mail: xxxxxxxxxxxxxx).

2. Em nota de rodapé, são inseridos os dados do autor. (e. g. Professor do Departamento de Matemática da PUC-SP. E-mail: xxxxxxxxxxxxxx).
} 
preparam as avaliações e os estudantes realizam-nas para formalizar o regimento da instituição e, assim, cumprir o conteúdo programático. Nessa preparação, com a implementação da Base Nacional Comum Curricular (BNCC) e da Deliberação CEE 155/2017, no Estado de São Paulo, os documentos, por serem normativos, precisam ser referenciados. Contudo, os professores, muitas vezes, enfrentam dificuldades para a implementação de tais documentos, tanto no alinhamento dos componentes curriculares, quanto na utilização do que estava sendo proposto.

O presente artigo tem como objetivo analisar as concepções de aprendizagem e de avaliação dos professores, no ensino da Matemática, considerando as diretrizes da Base Nacional Comum Curricular e da Deliberação CEE 155/2017. Para tal, inicialmente, discorremos sobre os documentos oficiais - BNCC e Deliberação CEE 155/2017. Em seguida, explicitamos o conceito de avaliação e, na parte final, apresentamos a análise dos dados coletados e algumas conclusões.

\section{Dos Parâmetros Curriculares Nacionais (PCN) ao documento da BNCC}

Antes de apresentarmos o documento da BNCC, recorremos aos PCN com a intenção de termos mais elementos para compreender como a questão da avaliação era tratada antes de sua implementação. Um dos instrumentos de avaliação sugeridos pelos Parâmetros Curriculares Nacionais é a avaliação investigativa. Nela, o docente consegue informações importantes a respeito da compreensão do conteúdo abordado pelo aluno, ajudando o docente a acompanhar como o conteúdo está sendo ensinado e reelaborado pelo aluno. Analisando os PCN, percebemos duas funções no campo da avaliação: uma dimensão social e a outra dimensão pedagógica.

A dimensão social possibilita que os envolvidos na aprendizagem - estudantes e professores obtenham informações sobre a assimilação dos objetivos propostos, permitindo aos estudantes identificar suas deficiências, amadurecendo a capacidade de discernir onde se encontra o erro no exercício proposto. Em compensação, para os professores, abre a possibilidade de dividir com os estudantes se esses objetivos foram atingidos, demonstrando assim, que o assunto abordado será útil para sua futura vida profissional.

A dimensão pedagógica está mais associada aos professores, pois fornece informações sobre a aprendizagem dos estudantes e como ela está acontecendo. Proporciona também, a linha de pensamento, o raciocínio, as estratégias utilizadas na resolução e a forma como foram finalizados os exercícios propostos na avaliação.

Seguindo as orientações dos Parâmetros Curriculares Nacionais, fica claro que as avaliações são instrumentos importantes para dar subsídios do desempenho dos alunos e para que o professor adeque seus instrumentos avaliativos à realidade dos sujeitos envolvidos, pois sabe-se que cada estudante possui características diferentes. Além disso, o aprendizado está intimamente ligado a um 
contexto que vai muito além da sala de aula: família, meio social, condição socioeconômica, capacidade cognitiva, patologias, entre outros.

A Base Nacional Comum Curricular estava prevista na Constituição de 1988 e surgiu da necessidade de um alinhamento dos currículos escolares de todo território nacional, como consta no artigo 210 da Constituição Federal do Brasil:

Serão fixados conteúdos mínimos para o ensino fundamental, de maneira a assegurar formação básica comum e respeito aos valores culturais e artísticos, nacionais e regionais. (BRASIL, 1988)

A BNCC, diferentemente dos PCN, apresenta de forma detalhada as habilidades e as competências, traduzidas em expectativas de aprendizagem que os alunos precisam alcançar ao término do ano letivo. Trata-se de documento normativo que propõe o estabelecimento de competências. O documento define competência como sendo:

Art. $3^{\circ}$... a mobilização de conhecimentos (conceitos e procedimentos), habilidades (práticas cognitivas e socioemocionais), atitudes e valores, para resolver demandas complexas da vida cotidiana, do pleno exercício da cidadania e do mundo do trabalho. (BRASIL, 2017, p. 4)

Com relação aos conteúdos a serem ensinados no campo da matemática não há grandes mudanças no que estava escrito nos Parâmetros Curriculares Nacionais. Constatamos apenas que os conteúdos foram reorganizados e renomeados como objetos de conhecimento e os objetivos, como habilidades. Vale destacar que alguns conteúdos do Ensino Médio foram antecipados para o Ensino Fundamental Anos Finais.

Nos Anos Iniciais do Ensino Fundamental temos a inserção do pensamento algébrico. Já, nos Anos Finais, a BNCC determina a introdução de novos objetos de conhecimento no ensino da Geometria, tais como: geometria das transformações, o plano cartesiano. Outra mudança que podemos destacar, refere-se a alteração do eixo que diz respeito ao tratamento da informação que passa a ter a nomenclatura de probabilidade e estatística com um maior uso das tecnologias.

Com relação ao campo da avaliação, no artigo 8 - parágrafo $\mathrm{V}$, a BNCC aponta a necessidade de:

V - Construir e aplicar procedimentos de avaliação formativa de processo ou de resultado, que levem em conta os contextos e as condições de aprendizagem, tomando tais registros como referência para melhorar o desempenho da instituição escolar, dos professores e dos alunos. (BRASIL, 2017, p.17)

Vale lembrar que é de responsabilidade dos Conselhos Estaduais de Educação orientar e fiscalizar o projeto político-pedagógico das instituições de ensino e acompanhar os procedimentos avaliativos e resultados obtidos. 
Embora seja um documento normativo, a BNCC permite uma flexibilização na elaboração dos processos de avaliação, fornecendo assim, a liberdade de escolha dos instrumentos a serem utilizados, desde que as orientações do artigo 8, parágrafo V sejam seguidas. Como não há orientações padronizadas, fica a critério do professor/escola a decisão do que será feito.

\section{Conselho Estadual de Educação de São Paulo - deliberação CEE 155/2017}

O Conselho Estadual de Educação (CEE) é uma organização que determina normas e regras para os sistemas de ensino público e privado no âmbito estadual e municipal, no nível da Educação Básica. Cabe ao conselho autorizar, fiscalizar e determinar o funcionamento das instituições de ensino e verificar se estão cumprindo os regimentos estabelecidos, tais como: ofertar as disciplinas, a carga horária e o corpo docente. É um órgão técnico, com autônima para fixar pareceres, indicações e deliberações e medidas de melhorias das políticas educacionais.

Além disso, cabe ao CEE:

através de seus pronunciamentos e de seus atos, definir a sua vocação como órgão não apenas técnico, mas político. Nesse sentido ele precisa - através de pareceres, indicações e deliberações - fixar posições que expressem as diretrizes fundamentais de uma política educacional para o Estado, levando em conta não apenas a realidade educacional presente como também as perspectivas de sua melhoria a médio e longo prazos. (CEE, 1997, p. 818)

Em 2017, o CEE, na deliberação 155/2017, dispõe sobre avaliação de alunos da Educação Básica, nos níveis fundamental e médio, no Sistema Estadual de Ensino de São Paulo e dá providências correlatas. Nela temos as diretrizes de como as escolas deveriam acompanhar o processo de aprendizagem e avaliação dos alunos. No artigo 16, da deliberação, está expresso que:

As propostas pedagógicas das escolas devem indicar com clareza as aprendizagens que devem ser asseguradas aos alunos nos níveis fundamental e médio da Educação Básica, nas diferentes áreas e componentes curriculares (2017, p. 03).

Já com relação ao modelo avaliativo, temos no artigo 17 as orientações a serem seguidas pelas escolas. São elas:

I - assumir um caráter processual, formativo e participativo, ser contínua, cumulativa e diagnóstica, com vistas a:

a) identificar potencialidades e dificuldades de aprendizagem e detectar problemas de ensino; b) subsidiar decisões sobre a utilização de estratégias e abordagens de acordo com as necessidades dos alunos, criar condições de intervir de modo imediato e a mais longo prazo para sanar dificuldades e redirecionar o trabalho docente;

II - utilizar vários instrumentos e procedimentos, tais como a observação, o registro descritivo e reflexivo, os trabalhos individuais e coletivos, os portfólios, exercícios, provas, questionários, dentre outros, tendo em conta a sua adequação à faixa etária e às características de desenvolvimento do educando;

III - fazer prevalecer os aspectos qualitativos da aprendizagem do aluno sobre os quantitativos, bem como os resultados ao longo do período sobre os de provas finais, quando 
essas ocorrerem, tal como determina a alínea "a" do inciso V do art. 24 da Lei no 9.394/96. (CEE, 2017, p. 03)

Resumidamente, a proposta de avaliação expressa na Deliberação 155/2017 defende um conceito de avaliação que precisa ter um olhar diferenciado em relação à contextualização dos objetos de conhecimento, levando em conta o conhecimento de mundo do aluno, bem como os conhecimentos prévios necessários à resolução de cada atividade proposta, despertando no educando a curiosidade e revelando a ele, a aplicação desses objetos de conhecimento.

\section{O conceito de avaliação: a visão de alguns autores}

Weisz, (2009) em seu livro “O diálogo entre o ensino e aprendizagem”, afirma que o processo de aprendizagem não deveria se limitar ao aluno como único sujeito no processo, mas, aos dois envolvidos: alunos e professores. Para que ele aconteça, é necessário criar um ambiente afetivo, com uma escuta atenta as falas das crianças. Além disso, o planejamento de atividades deveria evidenciar o desenvolvimento sociocognitiva do aluno, oferecendo situações desafiadoras, num contexto colaborativo.

Atualmente, o processo de avaliação continua sendo classificatório para a maioria das intuições educacionais que por meio de notas, balizam os níveis de aproveitamento dos alunos ao longo do período letivo e utiliza recursos avaliativos diversificados.

Por outro lado, a avaliação classificatória permite ao estudante um retorno rápido do resultado da atividade aplicada, mas não do seu aprendizado. Para Hoffmann (2009), devemos utilizá-la apenas como um ponto de partida, mas não como um processo completo de aprendizagem. Segundo a visão da autora:

\footnotetext{
Na concepção de avaliação classificatória, a qualidade se refere a padrões preestabelecidos, em bases comparativas: critérios de promoção (elitista, discriminatório), gabaritos de respostas às tarefas, padrões de comportamento ideal. Uma qualidade que se confunde com a quantidade, pelo sistema de médias, estatísticas, índices numéricos dessa qualidade. Contrariamente, qualidade, numa perspectiva mediadora de avaliação, significa desenvolvimento máximo possível, um permanente "vir a ser", sem limites preestabelecidos, embora com objetivos claramente delineados, desencadeadores da ação educativa. Não se trata aqui, como muitos compreendem, de não delinearmos pontos de partida, mas, sim, de não delimitarmos ou padronizarmos pontos de chegada. (HOFFMANN, 2009, p. 31-32).
}

Apesar de não ser enfática, a visão de Perrenoud (1999), em alguns de seus textos, condiz com a forma de avaliação classificatória, quando associa a aprendizagem a uma lógica tradicional e relaciona a uma hierarquia de excelência. A avaliação classificatória serve apenas para atribuir nota ou menção, não visa o aprendizado e apenas cumpri o papel de selecionar.

Como podemos observar, para Perrenoud: 
Os alunos são comparados e depois classificados em virtude de uma norma de excelência, definida no absoluto ou encarnada pelo professor e pelos melhores alunos". (PERRENOUD, 1999, p. 11).

A avaliação classificatória está associada a uma educação da pedagogia tradicional e precisamos desassociar do processo de ensino aprendizagem, mas infelizmente como ainda está associada a exames externos fica difícil para alguns docentes entenderem a diferença deste tipo de avaliação, pois ela não é a única ferramenta no processo de ensino.

Avaliação diagnóstica é parte importante no processo de ensino, como o próprio diz diagnostica a aprendizagem do aluno em anos anteriores e também ao longo do período letivo que o professor e aluno estão inseridos.

Para Hoffmann (1991) avaliar é um processo investigativo e democrático. O processo investigativo que ela propõe não está exatamente associado a provas, mas sim a conhecer o estudante num contexto amplo. Dialogar com o aluno é uma forma investigativa de começar a conhecer o quanto desenvolveu-se em anos anteriores e ajudá-los a seguir adiante.

o processo avaliativo a que me refiro é um método investigativo que prescinde da correção tradicional, impositiva e coercitiva. Pressupõe, isso sim, que o professor esteja cada vez mais alerta e se debruce compreensivamente sobre todas as manifestações do educando. (HOFFMANN, 1991, p. 79).

A avaliação diagnóstica é uma busca contínua de compreender as dificuldades dos estudantes e readequar a prática pedagógica para propiciar oportunidades de desenvolvimento amplo do conhecimento.

Avaliações formativas são estimuladas por se diferenciarem das formas de avaliações tradicionais, visto que utilizam vários instrumentos avaliativos, como, observação, diálogos com os estudantes, trabalhos em grupos, autoavaliação, seminários e entre outros métodos de livre escolha do docente.

Avaliações formativas têm a incumbência de fornecer dados constantes do processo de aprendizagem. Perrenoud (1999) defende que a avaliação formativa não é trabalhosa, desde que tenha objetividade, se bem utilizada reúne informações importantes.

Uma avaliação mais formativa não toma menos tempo, mas dá informações, identifica e explica erros, sugere interpretações quanto às estratégias e atitudes dos alunos e, portanto, alimenta diretamente a ação pedagógica, ao passo que o tempo e a energia gastos na avaliação tradicional desviam da invenção didática e da inovação. (PERRENOUD, 1999, p. 68)

Para Luckesi (1998), a avaliação formativa é um processo contínuo que possibilita reunir informações acerca do desempenho do estudante, pode ser realizada a partir de coleta de dados, análises e síntese e, assim com essas informações, professor e aluno possam determinar e corrigir 
caminhos para a melhoria da aprendizagem, mas o professor precisa estar comprometido e acreditar neste processo.

Finalizando com os autores selecionados, Hoffmann se mostra favorável à coleta de dados e que essas informações coletadas podem acontecer de maneiras diversificadas, como por exemplo, dialogando com o estudante, pois acredita que devemos considerar a individualidade do aluno.

Hoffmann (1988) aconselha que o docente antes de tomar alguma decisão precisa antes de mais nada analisar o desempenho deste estudante na sua totalidade. Nas palavras de Hoffmann (1998):

\begin{abstract}
Nenhuma decisão sobre os alunos deverá ser tomada sem uma extensiva análise do seu desempenho, através da observação e interpretação da sequência de suas tarefas e manifestações e pelo coletivo dos educadores que trabalham com ele. (HOFFMANN, 1998, p. 39)
\end{abstract}

Para a autora, o qualitativo deve prevalecer sobre o quantitativo.

A avaliação formativa se mostra eficaz no sentido que envolve professor e aluno, ela permite tanto ao professor quanto ao aluno compreender em que fase de aprendizagem se encontram.

A avaliação somativa, documenta o desenvolvimento do estudante e ocorre sempre ao final do processo de ensino e aprendizagem.

O objetivo desta avaliação é fornecer informações sobre os resultados da aprendizagem, mas para que isso ocorra precisa ter parâmetros específicos, por se tratar de uma avaliação que informa os resultados, o professor terá a capacidade de classificar qualitativamente o estudante e, por este motivo, acontece geralmente no final de cada processo, pois a finalidade da avaliação formativa é verificar o avanço do estudante, para tomada de decisão para a próxima fase ou período de aprendizagem.

Dessa forma, foram apresentadas as principais concepções de avaliações, mas de nada adianta tanto conhecimento, tantas leituras e discussões, se a avaliação continua sendo aplicada da mesma forma que antigamente.

No ensino da matemática, muitos professores se mostram relutantes com relação ao tipo de aplicação, acreditam que a avaliação precisa ser aplicada por meio de provas que mensuram o aprendizado por uma nota, predominando a avaliação classificatória. Em algumas situações, sem perceber, o professor de matemática está desempenhando uma avaliação formativa, mas não sabe como utilizá-la, acreditando que apenas atribuir notas ou menção seria suficiente para o desenvolvimento do aprendizado, independente se o aluno aprendeu ou não.

Luckesi (1998) nos ensina que avaliar é um:

ato amoroso, na medida em que a avaliação tem por objetivo diagnosticar e incluir o educando pelos mais variados meios, no curso da aprendizagem satisfatória, que integre todas as suas experiências de vida (LUCKESI, 1999, p. 173). 
Avaliar vai muito além de aplicar atividades avaliativas, é um processo que passamos ao longo de nossas vidas. Quando o estudante compreender que a avaliação faz parte de um processo contínuo do ensino e aprendizado e que fornece informações importantes do seu desenvolvimento, a avaliação passará a dar sentido para o estudante.

\section{A escolha do método, os instrumentos e a análise dos dados}

A escolha por uma pesquisa com abordagem qualitativa descritivo-analítica tem como principal argumento a seu favor a possibilidade de compreender as particularidades e experiências dos entrevistados, aproveitando sua vivência profissional no ensino da matemática dos anos finais do ensino fundamental.

André (2013), em seu artigo “O que é um estudo de caso qualitativo em educação”, nos chama atenção para a escolha do tipo de pesquisa empregar nossos estudos científicos:

\footnotetext{
Na perspectiva das abordagens qualitativas, não é a atribuição de um nome que estabelece o rigor metodológico da pesquisa, mas a explicação dos passos seguidos na realização da pesquisa. (ANDRÉ, 2013, p. 96)
}

As entrevistas, suas transcrições enriqueceram as análises com materiais únicos e importantes. André (2013) comenta sobre a coleta de dados: "todos os dados da realidade são considerados importantes" (ANDRÉ, 2013, p. 12).

O contato entre o entrevistador e o entrevistado proporcionou um rico material de estudo para a confecção e estruturação das informações que subsidiaram o presente artigo.

\section{$O$ contexto e os participantes da pesquisa}

Quatro professores participaram do presente estudo: Alfa, Beta, Gama e Ômega. Todas são professores da disciplina de Matemática de um instituto de ensino privado situado em uma cidade localizada no Grande ABC-SP, que conta com aproximadamente 1700 alunos matriculados, dos quais 800 alunos estão matriculados no ensino fundamental anos finais, distribuídos em turmas de aproximadamente trinta e cinco alunos, sendo estas seis de $6^{\circ}$ anos, cinco de $7^{\circ}$ ano, cinco de $8^{\circ}$ ano e quatro de $9^{\circ}$ ano.

Todas as respostas foram gravadas e transcritas na íntegra e, após leitura recorrente, conseguimos identificar duas categorias para análise. São elas: "fundamentos da ação docente e aprendizagem da docência" e "concepções de aprendizagem e os processos avaliativos". A seguir, apresentamos a análise seguindo as categorias elencadas. 


\section{Fundamentos da ação docente e aprendizagem da docência}

Este eixo teve o propósito de investigar, sob a ótica do professor, quais os referenciais teóricos que sustentam suas práticas. Essa é uma questão importante, porque a partir dela, teremos a clareza da concepção de aprendizagem que fundamenta a prática docente dos entrevistados.

Realizamos as seguintes perguntas aos docentes: em que fundamenta sua ação docente, pedindo para citar exemplos de práticas relacionadas com essas fontes/fundamentação e de que forma eles aprenderam a avaliar o aluno. As respostas dadas forneceram elementos para a compreensão de como os professores estão fundamentando suas ações pedagógicas e como concebem a aprendizagem da docência. Na primeira pergunta, a maioria dos professores respondeu que não possui uma concepção de aprendizagem definida, tanto que a maioria não conseguiu citar um exemplo prático de uma possível relação teoria e prática. As falas a seguir ilustram essa afirmação.

\footnotetext{
Alfa: Na verdade, a gente constrói junto com o aluno. Para mim são os dois caminhando juntos. Então socioconstrutivista.

Beta: Não sigo uma linha direta, sempre fiz de uma forma intuitiva. Eu não tenho uma classificação para o que eu faço. [...].

Gama: é uma mistura, pego as concepções do que eu já aprendi, vou pegando exemplos de professores meus e que deram certo. [...]

Ômega: Quando eu comecei na outra escola, eu fiz uma faculdade que fazia muito a linha construtivista, e comecei a lecionar em uma escola pequena, éramos incentivados a usar o construtivismo. Então eu era da linha do construtivismo.
}

A partir do referencial teórico, quando definimos o que é avaliação e quando concebemos a avaliação na prática, segundo alguns autores como Mizukami (1986) e Weisz (2009), é importante que o professor, nesta definição, tenha a clareza das concepções teóricas que sustentam a sua prática, pois a teoria e prática estão interligadas. O conceito de avaliação parte de uma concepção teórica de aprendizagem.

Com a intenção de avançarmos no entendimento do que os professores pensam sobre os processos avaliativos, perguntamos como eles aprenderam a avaliar. A maioria respondeu que o aprendizado é resultante da prática institucionalizada. Além disso, a maioria afirma que a formação inicial não foi suficiente para pensar as práticas avaliativas no contexto escolar. As falas a seguir ilustram essa afirmação:

\footnotetext{
Alfa: $\mathrm{Na}$ faculdade, eles não me ensinaram a avaliar o aluno, eu fui aprendendo conforme ia dando aula.

Beta: Não aprendi. Na época em que eu fiz a faculdade, não falava: "Você avalia desse jeito", eu fiz, como fizeram comigo, eu procurei fazer com que o aluno entendesse o que ele estava aprendendo, $[\ldots]$

Gama: Eu não aprendi, avaliar é uma coisa que a gente vai aprendendo sempre, hoje ela é instantânea quando deveria ser conceitual. [...]

Ômega: Não aprendi na faculdade. Eu, na verdade, aprendi no dia a dia, [...]
} 
Ao analisar as falas dos professores, podemos perceber que eles se mostraram distantes de uma reflexão coletiva da sua prática, pois nenhum deles afirmou que discutem com seus colegas seus processos avaliativos. Com relação à formação inicial, compactuamos com a ideia de que é um período inicial de todo um processo de desenvolvimento profissional. Logo, não é suficiente para contemplar tudo que o professor precisa saber para ensinar. Mizukami (2013) defende que:

o processo formativo inicial da docência tem funções e limites bem circunscritos: conhecimentos, habilidades, atitudes e valores não podem ser totalmente desenvolvidos no período a ser destinado. (MIZUKAMI, 2013, p. 27)

\section{Concepções de aprendizagem e os processos avaliativos}

Quando procuramos na literatura o que é avaliação, nos deparamos com muitos conceitos. Pensar nas concepções de avaliação pressupõe fazer relações com o que pensamos sobre aprendizagem. Neste sentido, dependendo das concepções de aprendizagem que defendemos empirismo, inatismo, construtivismo - teremos processos avaliativos diferenciados.

Com a intenção de conhecer como os professores compreendem o processo de aprendizagem dos alunos e, por sua vez, como pensam na avaliação, fizemos três perguntas: como o aluno aprende, porque o aluno não aprende e como ele sabe que o aluno aprendeu.

Em relação à primeira pergunta, identificamos na fala dos professores, uma concepção de aprendizagem distante de uma perspectiva construtivista. As respostas a seguir ilustram essa afirmação:

\footnotetext{
Alfa: Para criança aprender, o ambiente tem que ser propício, ela tem que se sentir segura a aprender. Ela deve construir seu conhecimento, com o professor sendo o facilitador.

Beta: Eu acredito que o aluno aprende em duas situações: quando aquilo que está estudando tem um significado para a vida dele ou quando treina muito, quando ele insiste e faz muito treino. [...]

Gama: Bom, matemática nas séries finais, sexto e sétimo ano, ele aprende executando, então eu preciso ensinar os procedimentos para ele, e ele vai executar a resolução desses exercícios em cima das regras propostas e vai evoluindo, né?! [...]

Ômega: É, então, eu acho que os alunos aprendem com o exemplo, com a explicação do professor, mas eu acho que essa é a menor parcela eu acho que o maior aprendizado é por experiência própria praticando, fazendo exercícios, errando. [...].
}

Ao analisar as respostas dadas pelos professores, constatamos que a visão deles de avaliação, provavelmente, está pautada numa concepção tradicional de avaliação: mais atenta aos resultados do que aos processos. Além disso, não identificamos nas respostas dadas que tanto professores quanto os alunos são elementos decisórios no processo de ensino e aprendizagem. Nesse sentido, podemos afirmar que essa postura dos professores vai ao encontro da perspectiva de avaliação como resultado, não sobrando tempo para as inovações, as retenções do saber e as cooperações entre professores e alunos. Perrenoud (1999) reforça que: 
Os professores beneficiam-se de uma autonomia ainda maior nos sistemas escolares que instituem uma avaliação contínua. Com efeito, a presença de provas anuais ou de provas padronizadas induz uma forma de harmonização pelo simples fato de que cada professor corre o risco de uma contradição entre seu modo de avaliar seus alunos e seus resultados em testes dos quais não domina nem o conteúdo, nem a tabela, nem mesmo, como no baccalauréat, a administração ou a correção (PERRENOUD, 1999, p. 31)

Com o objetivo de aprofundar esta discussão, solicitamos aos professores que falassem suas percepções a respeito de como ocorre o desenvolvimento da aprendizagem no aluno.

As respostas dadas reforçaram o que foi mencionado anteriormente, ou seja, o não aprendizado é resultado muito mais de uma ação que o aluno não realizou do que de uma atuação do ensino do professor. Assim, na visão dos professores, o fato de o aluno não aprender não dependia de sua atuação.

A seguir apresentamos alguns trechos que evidenciam o que foi apontado anteriormente:

\begin{abstract}
Alfa: Tem alguns fatores, principalmente aquele fantasma da matemática, o medo que existe na matemática, segundo muitos não sabem onde aplicar a matemática, se você fizer a ligação entre alguma coisa, os alunos gostam. [...]

Beta: Olha, o que eu vejo, são vários fatores, você tem o fator da sinapse cerebrais, que, às vezes, não acontece de ter a sinapse, ele não consegue, aquilo é travado; ele tem aquela coisa dos pais falando: "Isso é difícil, isso é horrível, isso é péssimo", então a criança já trava por conta disso. [...]

Gama: Existem vários fatores, a educação está desacreditada na sociedade, a escola deixou de ter um papel, a escola deixou de ser apenas aprendizagem e agora virou a sociedade. [...] Ômega: Eu acho que tem o esforço do aluno, que sem ele, o aluno não consegue entender. [...]
\end{abstract}

Ao analisar as falas dos professores, percebe-se que na visão deles o único sujeito responsável pelo aprendizado é o estudante. Logo, as respostas dadas contrariam o que Weisz (2009) defende: o processo de aprendizagem não se limita ao aluno como único responsável, pois, o professor também é elemento decisório. Para a autora,

São dois processos que se comunicam, mas não se confundem: o sujeito do processo de ensino é o professor, enquanto o do processo de aprendizagem é o aluno. É equivocada a expectativa de que o aluno poderá receber qualquer ensinamento que o professor lhe transmita exatamente como ele lhe transmite. (2009, p. 65).

Por último, na tentativa de identificar as concepções de aprendizagem dos professores, perguntamos como eles sabem se o aluno aprendeu. Eles responderam:

Alfa: Quando o aluno demonstra por meio do diálogo, pelas atividades desenvolvidas em aula, percebo que o aluno se abre mais para perguntas, se mostra interessado, ali sinto que meu aluno está aprendendo, mesmo cometendo alguns erros.

Beta: Ele precisa estar com uma disponibilidade de querer aprender e aquilo tem que ser prazeroso para ele, não pode ser: [...]

Gama: Quando vira uma chave, a criança que vira e fala "Puts, então é assim, porque isso conecta com isso" ele dá um salto tão grande que ele mesmo se surpreende, então ele sai do passo a passo e vai para o cálculo mental. 
Ômega: Quando ele mostra um pensamento organizado e ele consegue justificar esse pensamento através de um desenvolvimento de um problema, ele está me mostrando que ele aprendeu de forma oral ou escrita.

Os professores afirmaram que utilizam de diferentes situações para saber se o aluno aprendeu. São elas: por meio do diálogo, na realização de atividades desenvolvidas em sala, na demonstração de interesse do que está sendo proposto, na resolução do problema, e na verbalização do percurso (tanto pela linguagem oral quanto pela linguagem escrita). Contudo, a professora Ômega foi a única que na resposta dada também demonstrou preocupação em conhecer como o aluno aprendeu. Numa perspectiva de avaliação que considere mais o processo (como o aluno está aprendendo) do que o produto (o que o aluno sabe) o professor tem condições de organizar intervenções propícias para o aprendizado do aluno.

Dando continuidade às entrevistas, as próximas perguntas estavam relacionadas às concepções de avaliação. São elas: qual a função da avaliação, quais critérios de avaliação e quais instrumentos de avaliação que eles utilizam. Com relação à função, os professores responderam que a avaliação cumpre apenas a função de medida e de verificação de aprendizagem. Os depoimentos a seguir ilustram esta afirmação:

\begin{abstract}
Alfa: Na minha opinião é muito de modismo e a escola pede para que você seja de tal forma, antigamente era um modelo mais tradicional, se o cara não fez era aquela nota e tchau. [...] Beta: Eu acredito que a principal função da avaliação é identificar até onde o aluno aprendeu e dar ferramentas ao professor para retomar o que não ficou claro para o aluno.

Gama: Se houve progresso na aprendizagem e se o aluno consegue colocar no dia a dia, aplicando de forma correta. Ele pode saber como aplicar, mas ele tem que saber por que ele aplicou.

Ômega: Verificar o aprendizado do aluno, se eu consegui transmitir a matéria para o estudante e se ele consegue aplicar em uma situação de prova.
\end{abstract}

Com relação aos critérios de avaliação, a maioria mencionou que valoriza o processo mais do que o resultado. Elas disseram:

\begin{abstract}
Alfa: Lição, comportamento, as avaliações das provas (mensal, trimestral), recuperação.
Beta: Bom, eu preciso de uma organização do estudante, eu vou mais pelo que ele faz, do que pelo resultado. O processo para ver se, por exemplo, ele estava indo muito bem, aí ele não sabe multiplicar, logo ele me dá uma resposta errada. [...]

Gama: Nesse momento, eu preciso considerar todo o processo, se o aluno atingiu o conceito corretamente. Para mim, só consigo avaliar se ele acertou a questão corretamente, [...].

Omega: Eu levo em conta se ele conseguiu desenvolver o raciocínio, ele terá uma pontuação, eu não consigo considerar só o resultado. [...]
\end{abstract}

Entretanto, provavelmente essa preocupação esbarra no que é solicitado institucionalmente (provas, atividades etc.). Além disso, na fala da professora Beta identificamos algo que ainda é comum nas escolas: a visão que o erro deve ser evitado.

Luckesi (1998) defende diferentemente que "o erro não é fonte de castigo, mas suporte para o crescimento" (p. 58), errar leva ao amadurecimento e por este motivo não deve ser evitado, o erro 
cometido pelo aluno dá subsídios para o professor detectar em que momento do aprendizado se encontra e quais metodologias deverá adotar para a construção do conhecimento. Para o autor:

\begin{abstract}
Os erros da aprendizagem, que emergem a partir de um padrão de conduta cognitivo ou prático já estabelecido pela ciência ou pela tecnologia, servem positivamente de ponto de partida para o avanço, na medida em que são identificados e compreendidos, e sua compreensão é o passo fundamental para a sua superação. (LUCKESI, 1998, p. 57)
\end{abstract}

Com relação aos instrumentos de avaliação, os professores utilizam predominantemente as avaliações institucionais. Cumpre ressaltar que a composição da nota do aluno é determinada institucionalmente: - 60\% com avaliação trimestral e simulado; - 10\% participação do aluno e $30 \%$ a critério do professor.

\begin{abstract}
Alfa: Avaliava a participação em sala de aula, vejo a participação na aula, avaliação por prova escrita e, às vezes, trabalho em grupo.

Beta: Se eu falar do colégio ..........., nós temos umas normas da escola, então atividades avaliativas, a prova objetiva, a prova dissertativa e questões contextualizadas. [...].

Gama: Eu utilizo vários, mas hoje o formal (provas trimestral e mensal). Eu gosto de avaliar subjetiva, passo olhando os cadernos, faço lista de exercícios, faço interferência que faz com que o aluno progrida.

Omega: Utilizo as provas oficiais, trimestrais e parciais. Agora avaliar o processo é muito difícil, vejo se ele faz a lição, se ele tem dúvidas. [...]
\end{abstract}

Ao analisarmos as respostas dadas pelos professores, percebemos uma grande preocupação em seguir o regimento da instituição, faltando espaço para um instrumento avaliativo formativo, as ferramentas mencionadas estão mais voltadas para uma avaliação tradicional.

Na intenção de verificar como os professores acompanham seus alunos durante e após o processo de aprendizagem, foram feitas três perguntas. Na primeira, a intenção era analisar como o professor enxerga o erro e como ele pensa a sua intervenção. Com a segunda, procuramos identificar como é feito o feedback e, por último, quais as condições o aluno deveria ser reprovado.

Ao analisar as falas dos professores, a maioria relata que enxerga o erro como algo importante no desenvolvimento do aluno. Disseram que a partir do erro cometido, conseguem compreender o pensamento do aluno. Foi relatado também que utilizam como ferramenta de diagnóstico, aproveitando para discussão em aula. Contudo, identificamos na fala de dois professores a ideia de que a constatação do erro deve ser evitada, ou seja, ao mesmo tempo que afirmam que o erro é um caminho, também mencionam que deve ser evitado. Com relação às intervenções que utilizam, a maioria respondeu que retomam o objeto de conhecimento que não foi assimilado pelo aluno. As falas a seguir ilustram o que foi dito anteriormente:

Alfa: Maravilhoso o erro, é fundamental o erro, eu sempre falo: "Não tenham medo do erro, o erro faz parte do acerto, não importa quantas vezes você errou e não tenha medo de errar". [..] 
Beta: O erro é um diagnóstico para ver onde temos que voltar com a matéria, eu preciso saber o que e até onde o aluno entende para que eu faça as minhas intervenções para que ele não se equivoque mais que aquilo. [...]

Gama: Eu vejo o erro e falo "Presta atenção aqui, respira, vamos fazer junto, qual a pergunta você não fez para o seu cérebro?". Eu incentivo esse tipo de conversa[...]

Ômega: Eu sempre falo: “é melhor tentar e errar do que não tentar", não tem problema errar o importante é tentar. [...]

As respostas dadas compartilham o pensamento que Hoffmann (2001) mostrando que o professor deve estar atento ao aluno como um todo, apoiando o estudante na conquista do conhecimento. Neste sentido, o professor deve:

[...] assumir a responsabilidade de refletir sobre toda a produção de conhecimento do aluno, promovendo o movimento, favorecendo a iniciativa e a curiosidade no perguntar e no responder e construindo novos saberes junto com os alunos. (HOFFMANN, 2001, p. 75)

Para dar andamento a esse entendimento, perguntamos aos professores como eles organizam o feedback. A finalidade desta pergunta é entender como é realizado o acompanhamento durante o processo de aprendizagem.

A grande maioria respondeu que realiza o feedback após a avaliação institucional. Além disso, os professores disseram que utilizam momentos da aula para fazer a correção coletivamente e, quando necessário, individualmente.

\footnotetext{
Alfa: Eu faço individual, na prova escrita, primeiro corrijo com todos e depois com cada um eu explico por que errou, e aí descubro onde tenho que trabalhar mais.

Beta: Depende da situação, às vezes, eu faço um geral, mas dependendo eu falo com o aluno sozinho, eu dou uma lista para ele que não é a mesma dos outros, falo olha você precisa treinar isso, eu prefiro trabalhar com feedback individual.

Gama: Organizo em vários momentos, primeiro eles recebem a prova na minha mesa de forma individual e comento os erros e os acertos, eu retomo sempre individualmente com o aluno.

Ômega: Em uma sala pequena, o feedback individual é mais fácil, mas algum comentário na prova, na atividade, mas se o aluno vem questionar, eu explico, porém algo a fundo não consigo pela quantidade de aluno em sala de aula.
}

Ao analisar as respostas, os professores demonstraram desconhecer a utilização do feedback que deveria ocorrer ao longo do processo de aprendizagem e não apenas após a avaliação institucional.

As falas anteriores comparadas com as falas apresentadas acima apontam algumas contradições, ou seja, ao mesmo tempo que eles consideram o erro como elemento importante no processo de aprendizagem, contudo, o feedback é feito após as avaliações institucionais.

O feedback é importante porque auxilia tanto o aluno quanto o professor no processo de aprendizagem. Para o professor é possível a identificação do nível de desempenho do aprendizado 
em que o aluno se encontra e qual direção deverá seguir na sua prática de ensino. Quanto ao aluno será uma ferramenta útil de orientação e direcionamento para seu aprendizado.

A ideia de reprovação é algo que está presente em muitos contextos educacionais. Com a intenção de conhecermos o que os professores pensam a respeito da reprovação, perguntamos em que condições o aluno deveria ser reprovado.

A maioria dos professores disse que a reprovação deveria ser feita após esgotadas todas as possibilidades de ensino. Além disso, para eles, a reprovação é vista como uma oportunidade do aluno de ter mais tempo para aprender.

Para os entrevistados, o aluno deveria ser reprovado quando não assimilou o conteúdo mínimo trabalhado em aula. Vale ressaltar que não conseguimos perceber, nas respostas dadas, quais as estratégias de ensino que os professores utilizam para evitar a reprovação. As falas a seguir ilustram o que foi dito anteriormente:

\footnotetext{
Alfa: Quando eu ofereci tudo, esgotando todas as disponibilidades de ensino, o professor tem direito de reprovar o aluno.

Beta: Do jeito que temos as coisas hoje, você segue uma grade então $7^{\circ}$ ano tem que ser aquilo, $8^{\circ}$ ano tem que ser isso, então o aluno precisa ser reprovado quando ele não conseguiu as ferramentas para ir para o próximo ano, quando o próximo ano vai ser sofrível para ele. $[\ldots]$

Gama: Então, eu acredito na reprovação porque assim, a reprovação não significa que você não é bom, apenas que você precisa de mais um tempo, [...]

Ômega: Não vejo por que reprovar por uma disciplina, porque as pessoas têm talentos diferentes e se você reprova por uma matéria é desestimulante para esse estudante. [...].
}

Ao analisar as falas dos professores, podemos observar que há uma preocupação em relação ao objeto de conhecimento que não foram adquiridos durante o período letivo, pois para eles existe a necessidade de um conhecimento mínimo para o andamento do processo de aprendizagem para o ano seguinte, mas não ficou claro na fala dos professores uma preocupação com processo, faltou uma reflexão sobre o futuro do aluno.

Cumpre lembrar que os documentos oficiais, entre eles, a Deliberação CEE 155/2017, apontam a importância de se evitar a reprovação. Segundo o documento, para que a reprovação não ocorra, há um longo caminho a ser percorrido. De acordo com a deliberação:

Art. 17 A avaliação dos alunos, a ser realizada pelos professores e pela escola como parte integrante da proposta curricular e da implementação do currículo, é redimensionadora da ação pedagógica e deve:

I - assumir um caráter processual, formativo e participativo, ser contínua, cumulativa e diagnóstica, com vistas a:

a) identificar potencialidades e dificuldades de aprendizagem e detectar problemas de ensino; b) subsidiar decisões sobre a utilização de estratégias e abordagens de acordo com as necessidades dos alunos, criar condições de intervir de modo imediato e a mais longo prazo para sanar dificuldades e redirecionar o trabalho docente;

II - utilizar vários instrumentos e procedimentos, tais como a observação, o registro descritivo e reflexivo, os trabalhos individuais e coletivos, os portfólios, exercícios, provas, 
questionários, dentre outros, tendo em conta a sua adequação à faixa etária e às características de desenvolvimento do educando;

III - fazer prevalecer os aspectos qualitativos da aprendizagem do aluno sobre os quantitativos, bem como os resultados ao longo do período sobre os de provas finais, quando essas ocorrerem, tal como determina a alínea "a" do inciso V do art. 24 da Lei no 9.394/96. (CEE, 2017, p. 3)

Os indicadores são documentos importantes no processo de avaliação. Para complementar as entrevistas, perguntamos aos professores se os documentos os auxiliam no processo de avaliação.

Todos os professores afirmaram que não consideram, em seus processos avaliativos, os documentos oficiais: nenhum professor fez referência à Deliberação CEE 155/2017. Dois professores mencionaram a BNCC, porém, segundos eles, o documento mais atrapalha do que ajuda. Eles disseram:

\footnotetext{
Alfa: Ajudam a identificar como o aluno aprende, seja nas atividades, na prova.

Beta: Eu não sinto nenhuma ajuda de nenhuma dessas deliberações. Não sei no que as classificações possam me auxiliar nisso. [...]

Gama: Na verdade, eles me atrapalham, porque eu tenho que preencher tanta coisa, que eu deixo de focar no meu aluno, [...].

Ômega: Assim hoje temos que trabalhar com as habilidades, mas eu não gosto, eu acredito que são muito confusas. Eu não sei se ainda não compreendi, mas não acho que para todos os conteúdos funcionam. Os outros documentos não conheço a fundo.
}

Os documentos, em especial a Deliberação CEE 155/2017 no artigo 17, defendem uma avaliação formativa e que deva prevalecer o qualitativo sobre o quantitativo, documento esse que traz uma segurança e proteção para o aluno.

\footnotetext{
Art. 17 A avaliação dos alunos, a ser realizada pelos professores e pela escola como parte integrante da proposta curricular e da implementação do currículo, é redimensionadora da ação pedagógica e deve:

I - assumir um caráter processual, formativo e participativo, ser contínua, cumulativa e diagnóstica. (CEE, 2017, p. 7)
}

Constatamos, nas respostas dadas, que os professores visualizam os documentos mais como obstáculos do que como norteadores para suas práticas avaliativas. Tanto a deliberação quanto a BNCC propõem uma avaliação que seja formativa.

Os documentos não propõem estratégias de avaliação, mas expõem os princípios que deveriam nortear um processo avaliativo. Pensar em estratégias avaliativas pressupõem um conhecimento tanto do conteúdo que está sendo ensinado quanto dos conhecimentos didáticos envolvidos nos processos de aprendizagem.

Ao analisar as respostas dadas, avaliar vai muito além de verificar, medir. Avaliar é compreender o processo, pensar nos diferentes instrumentos diagnósticos, nas diferentes intervenções 
necessárias no momento certo. Aplicar provas e fazer verificação não significa acompanhamento do aprendizado. Avaliar é mudar metodologias que não estão surtindo efeitos.

Para Luckesi (1998), a avaliação deve ser inclusiva, a partir do momento que os professores se preocupam com a aplicação de uma avaliação diagnóstica e que após haja uma intervenção, o aluno trilhará os conhecimentos e as habilidades para uma aprendizagem completa. Segundo o autor:

Defino a avaliação da aprendizagem como um ato amoroso, no sentido de que a avaliação, por si só, é um ato acolhedor, integrativo, inclusivo. Para compreender isso, importa distinguir avaliação de julgamento. O julgamento é um ato que distingue o certo do errado, incluindo o primeiro e excluindo o segundo. (LUCKESI, 1998, p. 172)

Ao finalizar as análises, percebemos que os professores entrevistados ainda possuem um viés pela abordagem tradicional. Porém, em alguns momentos da análise, percebemos a aproximação com um conceito de avaliação sócio construtivista. Cumpre lembrar que na coleta de dados não observamos práticas avaliativas em sala de aula.

\section{Considerações finais}

Neste artigo, me propus a investigar as relações estabelecidas entre Base Nacional Comum Curricular e a Deliberação CEE 155/2017, procurando analisar os processos avaliativos utilizados pelos professores, no ensino da Matemática, que contemplam as diretrizes da Base Nacional Comum Curricular e da Deliberação CEE 155/2017.

Sabemos que um estudo se faz com a colaboração do referencial teórico. Weisz enriqueceu o estudo com materiais que trouxeram ensinamentos importantes sobre as concepções de aprendizagem, bem como Luckesi, Hoffman e Perrenoud que tratam dos conceitos de avaliação, enfim, autores que colaboraram com a análise dos dados gerados na pesquisa.

Os resultados das análises demonstraram que os professores não definiram explicitamente suas concepções de aprendizagem. Eles se aproximaram, em seus discursos, de uma abordagem tradicional de avaliação. Além disso, é por meio da experiência prática, no dia a dia, que aprenderam a avaliar seus alunos.

Quanto aos aspectos dos processos avaliativos foi preocupante saber que a grande maioria afirma que o aluno é visto como o único responsável pelo seu aprendizado. Em contrapartida, os professores utilizam diferentes instrumentos para avaliar - como diálogo, atividades diversificadas -, quando percebem que os alunos não estão conseguindo aprender o que está sendo ensinado.

Apesar de valorizarem o processo desenvolvido, constatamos que os professores veem a função da avaliação apenas como medida de verificação da aprendizagem, como o feedback, que é um exemplo 
de ferramenta dessa natureza. Neste caso, notamos que o seu uso ocorre após a realização das avaliações, sugerindo um desconhecimento da sua importância durante o processo de aprendizagem.

Nossas análises mostraram que o tema reprovação, para a maioria, é visto como uma oportunidade de aprendizagem eficaz, visto que para os entrevistados é necessário um conhecimento mínimo para a aprovação do aluno.

O estudo também revelou que os professores não acreditam que os documentos oficiais sejam importantes, sendo apenas protocolos instituídos como pro forma e que apenas atrapalham o andamento do ensino.

Todas as análises nos levaram a concluir que repensar os processos avaliativos demandam tempo e a desconstrução de conceitos internalizados. Isso só é possível através de um trabalho coletivo. Constatamos que os documentos oficiais apontam para uma avaliação que seja acolhedora e que promova a inclusão. Contudo, o que dá vida ao que está sendo proposto são os professores. Logo, precisamos propiciar espaços formativos que sejam coletivos para que as ações que ocorrem na sala de aula sejam revisitadas e repensadas.

Por fim, o estudo realizado demonstrou a necessidade de novos estudos que abordem este tema, visto que os documentos oficiais explanados serão reavaliados e sempre haverá a necessidade de nós, professores, coletivamente, repensarmos os processos avaliativos, pois eles são dinâmicos e importantes para aprendizagem.

Recebido em: 27/05/2021

Aprovado em: 21/12/2021

\section{Referências}

ANDRÉ, M. O que é um estudo de caso qualitativo em educação? Revista da FAEEBA - Educação e Contemporaneidade, Salvador, v. 22, n. 40, p. 95-103, jul./dez. 2013.

BRASIL. Ministério da Educação, Secretaria de Educação Fundamental. Parâmetros Curriculares Nacionais. Brasília, DF: MEC/SEF, 1997.

BRASIL. Ministério da Educação. Base Nacional Comum Curricular - BNCC Versão Final. Brasília, DF, 2017. Disponível em: $<$ http://portal.mec.gov.br/index.php?option=com_docman\&view=download\&alias=79611-anexotexto-bncc-aprovado-em-15-12-17-pdf\&category_slug=dezembro-2017-pdf\&Itemid=30192>. Acesso em 20/04/2019.

HOFFMANN, J. Pontos \& Contra pontos: do pensar ao agir em avaliação. 7 ed. Porto Alegre; Editora Mediação, 2003. 
HOFFMANN, J. Avaliação Mediadora: uma prática em construção da pré-escola à universidade. Porto Alegre; Editora Mediação, 2009.

HOFFMANN, J. Avaliar para promover: as setas do caminho. 7 ed. Porto Alegre; Editora Mediação, 2001.

LUCKESI, C. C. Avaliação da Aprendizagem Escolar: estudos e proposições. 7. ed. São Paulo: Cortez, 1988.

LUCKESI, C. C. Sobre notas escolares: distorções e possibilidades. São Paulo: Cortez, 2014.

MIZUKAMI, M. G. N. Ensino: as abordagens do processo. São Paulo: E.P.U., 2019.

PERRENOUD, P. Não mexam na minha avaliação! Para uma aprendizagem sistêmica da mudança pedagógica. In: ESTRELA, A.; NÓVOA, A. Avaliações em educação: novas perspectivas. Porto, Pt: Porto Editora, 1993, p.173.

PERRENOUD, P. Avaliação: da excelência à regulação das aprendizagens: entre duas lógicas; tradução Patrícia Chittoni Ramos - Porto Alegre: Artmed, 1999.

PERRENOUD, P. Construir as competências desde a escola. Trad. Brunos Charles Magne. Porto Alegre: Artmed, 1999.

SÃO PAULO. Comissão Estadual de Educação. Deliberação no 155/2017. Redação do artigo $9^{\circ}$ da Lei 10.403, de 6-7-1971. Publicado no DOE em 06/07/2017. Disponível em: http://www.educacao.sp.gov.br/lise/sislegis/detresol.asp?strAto=20170711s/n. Acesso em 05/02/2019.

WEISZ, T.; SANCHEZ, A. O diálogo entre o ensino e a aprendizagem. 2. ed. V. 1. São Paulo, Editora Ática, 2009. 